\title{
PITUITARY HYPERPLASIA MIMICKING MACROADENOMA SECONDARY TO PRIMARY HYPOTHYROIDISM
}

\author{
${ }^{1}$ Department of Pediatrics, University \\ Clinical Center Tuzla, Tuzla, Bosnia \\ and Herzegovina, ${ }^{2}$ Academy of Sciences \\ and Arts of Bosnia and Herzegovina \\ Sarajevo, Bosnia and Herzegovina \\ ${ }^{*}$ Corresponding author: \\ almatoromanovic@bih.net.ba \\ Tel.: + 38735303715 \\ Fax.: + 38735303730
}

Alma TOROMANOVIĆ ${ }^{*}$, Husref TAHIROVIĆ 2

Received: September 02, 2015

Accepted: November 27, 2015

Key words: Pituitary hyperplasia Hypothyroidism - Pituitary macroadenoma - Children - Thyroxine replacement therapy.

\begin{abstract}
Objective - We aim to emphasize the importance of extensive endocrine workup in cases of pituitary masses. Case report - We report on a case of pituitary thyrotrophic hyperplasia in a 12-year-old girl who was thought to have a pituitary macroadenoma with suprasellar extension. The main complaint was headache, while other symptoms of hypothyroidism were present, but weren't recognised. Hormonal testing revealed low total thyroxine $(<12.8 \mathrm{nmol} / \mathrm{l})$ and high TSH (310.5 mIU/l) levels, and hyperprolactinemia (prolactin level at 1680 $\mathrm{mIU} / \mathrm{l})$. Based on the clinical history, laboratory data, and MRI, a diagnosis of pituitary hyperplasia secondary to primary hypothyroidism, consequent to chronic autoimmune thyroiditis, was made. Therapy with levothyroxine was initiated at $50 \mu \mathrm{g} /$ day and gradually increased to $75 \mu \mathrm{g}$ daily. After three months of thyroxine replacement, she was clinically and biochemically euthyroid. A follow-up MRI, 4 months after thyroxine replacement was initiated, showed complete resolution of the mass, and normal pituitary gland. Conclusion - Primary hypothyroidism should be considered in the differential diagnosis of pituitary masses. Multidisciplinary assessment in these cases will help to avoid delays in diagnosis and prevent unnecessary surgery.
\end{abstract}

\section{Introduction}

Symptoms of hypothyroidism may be vague, and are often unrecognised for years, thus causing delay in the diagnosis (1). Thyrotrophic hyperplasia secondary to primary hypothyroidism has been previously reported in both adults and children (1-4), and can be large enough to mimic pituitary macroadenoma and compress the adjacent structures (2-5). Despite constant progress in imaging techniques, it is not yet possible to differentiate hyperplasia of pituitary thyrotroph cells from thyroid-stimulating hormone (TSH)producing macroadenoma by magnetic resonance imaging (MRI) alone. In such cases, a follow-up MRI after therapy with levothyroxin may provide a definitive diagnosis.

We report on a 12-year-old girl with primary hypothyroidism complicated by pituitary hyperplasia mimicking macroadenoma.

\section{Case report}

A 12-year-old girl was referred to our pediatric endocrinology clinic by neurosurgeon for evaluation, after a diagnosis of pituitary macroadenoma was made. She was born as a second child at 37 weeks of gestation by normal delivery with birth weight $2250 \mathrm{~g}$ and length $42 \mathrm{~cm}$. She had a history of de- 
velopmental delay. From the age of 2.5 years she was followed up by a neurologist in our institution for seizures. At the age of six years cranial MRI was done and revealed periventricular leukomalacia. Due to history of vertigo and headache a second cranial MRI was recommended by a neurologist at the age of 11 years. Imaging revealed a $10 \times 16 \times 17 \mathrm{~mm}$ (AP-CC-LL) intrasellar and suprasellar pituitary mass that homogeneously enhanced following administration of gadolinium contrast agent. The mass was elevating the optic chiasm (Fig. 1), bilaterally invading the cavernous sinus and encasing the internal carotid arteries for about $40 \%$. The pituitary stalk was along the midline. It was reported to be suggestive of a pituitary macroadenoma by radiologist.

Over the last one year she had complained of cold intolerance, chronic constipation, headache, fatigue, sluggishness, and difficulties in school. Her family confirmed weight gain and felt that she was growing slowly. Her growth chart confirmed that her height had decreased from the -1.4 SDS at 8.4 years, to the -2.5 SDS at 11.9 years. During the previous 3.5 years she had grown $10 \mathrm{~cm}$, while she gained $5 \mathrm{~kg}$ during the last year. She did not complain of any visual acuity or visual field changes. There was no family history of thyroid diseases.

On admission, her weight was $31.7 \mathrm{~kg}$ (between $5^{\text {th }}-10^{\text {th }}$ percentile) and height $129.3 \mathrm{~cm}(-2.5$ SDS). Physical examination revealed myxedema of the face, dry and pale skin, hoarseness of voice, acral coldness. Her heart rate was $68 / \mathrm{min}$, with distant heart sounds, and her blood pressure was 115/85 mmHg. On palpation thyroid gland was normal. Her breast and pubic hair were Tanner stage II. Neurologic examination showed right spastic hemiparesis with right Babinski sign and hyperactive deep tendon reflexes.

Laboratory investigation revealed normochromic anaemia, elevated total cholesterol of $8.59 \mathrm{mmol} / \mathrm{l}$ (normal range: 0-5.2), highdensity-lipoprotein cholesterol $1.76 \mathrm{mmol} / \mathrm{l}$ (normal range: 1.04-1.55), low-densitylipoprotein cholesterol $5.97 \mathrm{mmol} / \mathrm{l}$ (normal range: $0-3.3)$, and triglycerides of 1.68 $\mathrm{mmol} / \mathrm{l}$ (normal range: $0-1.7$ ). Hormonal analyses showed the serum free thyroxine (fT4) undetectable $0.0 \mathrm{pmol} / \mathrm{l}$ (normal range: 10-25), low level of total thyroxine (T4) $<12.8 \mathrm{nmol} / \mathrm{l}$ (normal range: 63-150.5) and free triiodothyronine (fT3) $1.6 \mathrm{pmol} / \mathrm{l}$ (normal range: 4.6-7.8), high level of thyroidstimulating hormone (TSH) of $310.5 \mathrm{mIU} / \mathrm{l}$
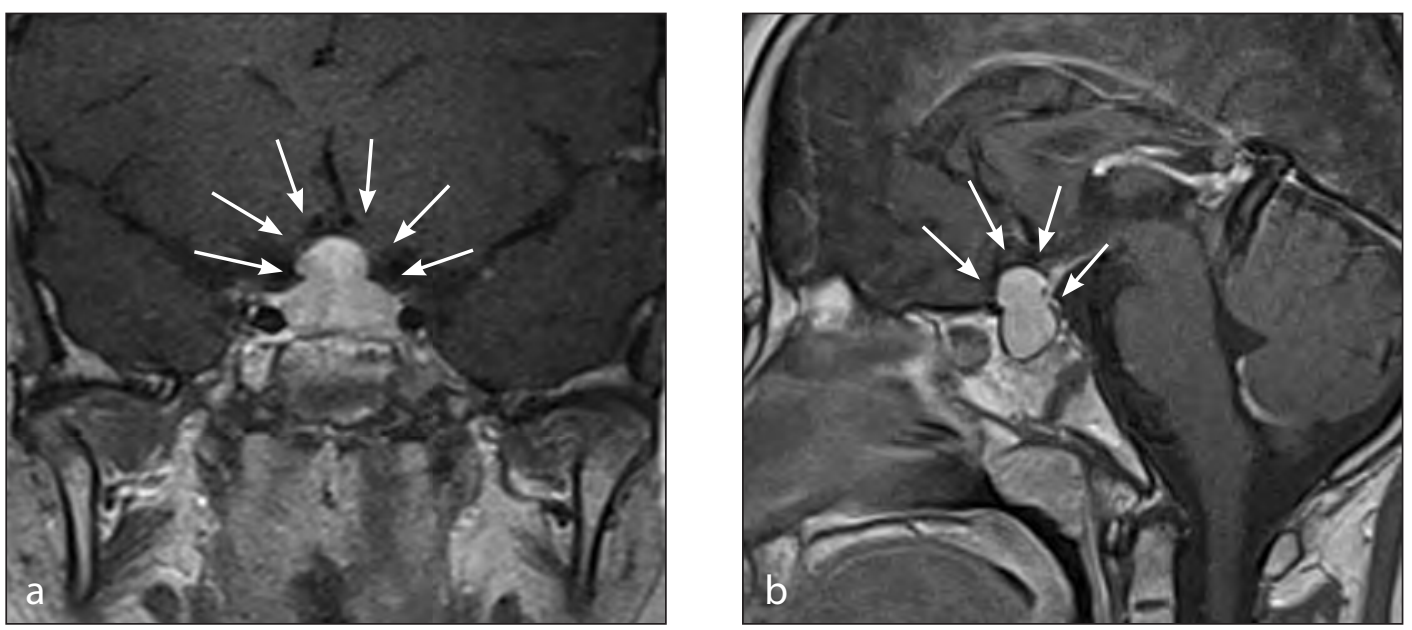

Fig. 1 Pretreatment MRI of the pituitary gland. Post-contrast T1-weighted coronal (a) and sagital (b) images show an enlarged pituitary gland with suprasellar extension. 

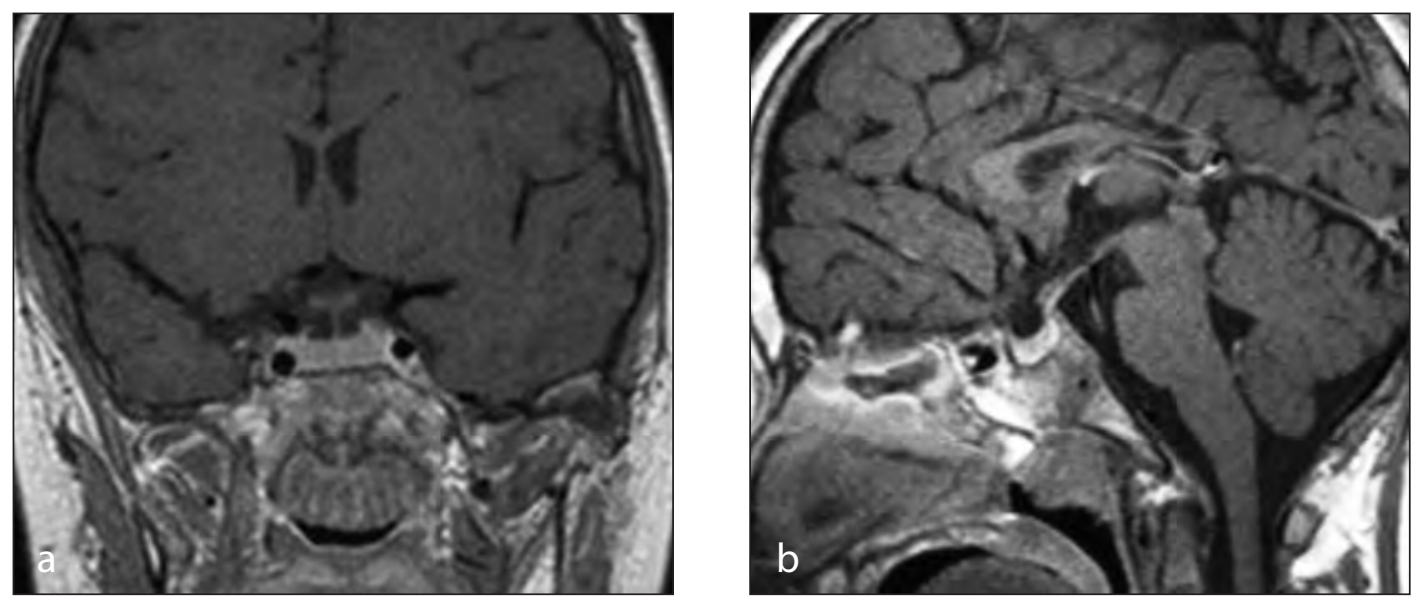

Fig. 2 Follow-up MRI of the pituitary gland after 4 months of levothyroxin treatment. Post-contrast T1-weighted coronal (a) and sagital (b) images show the complete resolution of the pituitary enlargement.

(normal range: $0.27-3.75$ ), as well as high titer of thyroid peroxidase antibodies of 519 $\mathrm{IU} / \mathrm{ml}$ (normal range: 0-60), and thyroglobulin antibodies $102.6 \mathrm{IU} / \mathrm{ml}$ (normal range: 0-60) indicating hypothyroidism caused by autoimmune thyroid disease. Serum level of prolactin was elevated at $1680 \mathrm{mIU} / \mathrm{l}$ (normal range: 90-523), and FSH (7.3 U/l), LH (3.2 U/l), estradiol $(0.099 \mathrm{nmol} / \mathrm{l}), \mathrm{IGF}-1$ (199.7 ng/ml), ACTH (42.4 pg/ml), cortisol (412 nmol/l) levels were all normal. Screening for celiac disease was negative.

Thyroid ultrasound revealed normal thyroid size with heterogeneous echo texture and hypo-echoic areas consistent with autoimmune thyroiditis. Bone age acording to Greulich and Pyle was 7 years and 9 months, thus delayed four years compared to chronological age. The ECG showed QRS microvoltage with inverted $T$ wave in limb leads (II and III) and precordial leads (V16). Echocardiography demonstrated a mild pericardial effusion. Ultrasound examination of the abdomen was normal. Visual field examination was not done due to child noncompliance.

Based on the clinical history, laboratory data, and MRI, a diagnosis of pituitary hyperplasia secondary to primary hypothyroid- ism, consequent to chronic autoimmune thyroiditis, was made. Therapy with levothyroxine was initiated at $50 \mu \mathrm{g} /$ day and gradually increased to $75 \mu \mathrm{g}$ daily. After three months of thyroxine replacement, she was clinically and biochemically euthyroid with the serum TSH level $2.1 \mathrm{mIU} / \mathrm{l}$ (normal range: 0.273.75) and fT4 $10.1 \mathrm{pmol} / \mathrm{l}$ (normal range: 10.0-22). The prolactin level had decreased to the normal range $(454 \mathrm{mIU} / \mathrm{l})$. A followup MRI, 4 months after thyroxine replacement was initiated, showed complete resolution of the mass, and normal-sized pituitary gland (Fig. 2).

\section{Discussion}

Pituitary hyperplasia is defined as a nonneoplastic increase in the number of one or more functionally distinct types of pituitary cells (6). It can occur as a normal response to physiological stimuli like pregnancy or as a pathological condition (6). Thyrotrophic hyperplasia results from the loss of thyroxine feedback inhibition and the subsequent overproduction of thyrotropin-releasing hormone (TRH) (7). Furthermore, TRH is likely an important cause of concomitant lactotroph hyperplasia linked to primary hypothyroid- 
ism (6). Therefore, mild to moderate hyperprolactinemia may occur in about three-quarters of patients (8), and it was also demonstrated in our case.

Children with pituitary hyperplasia mostly present with symptoms of hypothyroidism, like growth arrest and abnormal puberty, and rarely with neurological symptoms secondary to sellar expansion $(3,9)$. In some cases as in our case, headache may be the main complaint $(2,4)$. Prolonged primary hypothyroidism occasionally may lead to irreversible pituitary injury. It is important to realize that thyrotrophic hyperplasia can be large enough to mimic tumor and compress the adjacent structures, what needs to be kept in mind in order to avoid confusion with pituitary adenoma $(2-5,9,10)$. Despite recent progress, MRI still can not distinguish pituitary macroadenoma from hyperplasia. The MRI findings of pituitary hyperplasia overlap considerably with those of macroadenoma as was the case in our patient, where pituitary mass was reported as a macroadenoma.

Correct diagnosis is of vital importance, because unnecessary surgery may be avoided. Therefore, the diagnosis of thyrotrophic pituitary hyperplasia must rely on detailed endocrine investigation. Without endocrine workup, the pituitary mass in our patient was reported as a macroadenoma. After primary hypothyroidism was diagnosed in our patient, thyrotrophic pituitary hyperplasia was considered, which was confirmed by a complete resolution of the pituitary mass on the follow-up MRI scan that was done 4 months after initiation of levothyroxine replacement therapy. Complete regression of the pituitary mass after thyroxine replacement therapy has been described in the literature $(2-4,9-11)$ emphasizing the importance of endocrine investigation in the cases of pituitary masses. In cases of primary hypothyroidism associated with pituitary enlargement, MRI after therapy with thyroxine may provide a de- finitive diagnosis and eliminate unnecessary surgery. Surgery is rarely indicated in cases such as thyrotrophic hyperplasia with severe symptoms from mass effect not responding to thyroxine replacement therapy (12).

\section{Conclusions}

Primary hypothyroidism should be considered in the differential diagnosis of pituitary masses, especially in children with headache, growth arrest and abnormal puberty. Correct diagnosis is of vital importance in such cases. Therefore, to avoid delays in diagnosis and prevent unnecessary surgery, multidisciplinary approach is essential in the cases of pituitary masses.

Authors' contributions: Conception and design: AT; Acquisition, analysis and interpretation of data: AT, HT; Drafting the article: AT: Revising it critically for important intellectual content: AT, HT.

Conflict of interest: The authors declare that they have no conflict of interest.

\section{References}

1. Tahirović H, Toromanović A. Hashimoto's thyroiditis with consequent primary hypothyroidism. Paediatrics Today. 2009;5(1):94.

2. Simsek E, Simsek T, Savas-Erdeve S, Erdogmus B, Dosoglu M. Pituitary hyperplasia mimicking pituitary macroadenoma in two adolescent patients with long-standing primary hypothyroidism: case reports and review of literature. Turk J Pediatr. 2009;51:624-30.

3. Kocova M, Netkov S, Sukarova-Angelovska E. Pituitary pseudotumor with unusual presentation reversed shortly after the introduction of thyroxine replacement therapy. J Pediatr Endocrinol Metab. 2001;14:1665-9.

4. Franceschi R, Rozzanigo U, Fallo R, Bellizzi M, Di Palma A. Pituitary hyperplasia secondary to acquired hypothyroidism: case report. Ital J Pediatr. 2011;37:15.

5. Ghannam NN, Hammami MM, Muttair Z, Bakheet SM. Primary hypothyroidism-associated 
TSH-secreting pituitary adenoma/hyperplasia presenting as a bleeding nasal mass and extremely elevated TSH level. J Endocrinol. Invest. 1999;22:419-23.

6. Scheithauer BW, Horvath E, Lloyd RV, Kovacs K. Pituitary hyperplasia. Pituitary. 1998;3:281-9.

7. Koller KJ, Wolff RS, Warden MK, Zoeller RT. Thyroid hormones regulate levels of thyrotropinreleasing-hormone mRNA in the paraventricular nucleus. Proc Natl Acad Sci USA. 1987;84:732933.

8. Beck-Peccoz P, Brucker-Davis F, Persani L, Smallridge $\mathrm{RC}$, Weintraub $\mathrm{BD}$. Thyrotropin-secreting pituitary turmors. Endocr Rev. 1996;17:610-38.

9. Papakonstantinou O, Bitsori M, Mamoulakis D, Bakantaki A, Papadaki E, Gourtsoyiannis N. MR imaging of pituitary hyperplasia in a child with growth arrest and primary hypothyroidism. Eur Radiol. 2000;10:516-8.

10. Kanza RE, Gagnon S, Villeneuve H, Laverdiere D, Rousseau I, Bordeleau E, Berube M. Spontaneous ovarian hyperstimulation syndrome and pituitary hyperplasia mimicking macroadenoma associated with primary hypothyroidism. World J Radiol. 2013;28:20-4.

11. Ashley WW Jt, Ojemann JG, Park TS, Wippold FJ. Primary hypothyroidism in a 12-year-old girl with a suprasellar pituitary mass: rapid regression after thyroid replacement therapy: case report. J Neurosurg. 2005;102:413-6.

12. Wacharasindhu S, Shuangshoti S, Sunthornyothin S. TSH-Secreting Pituitary Macroadenoma in a Girl with Lingual Thyroid. Case Rep Endocrinol. 2013;2013:570847. 